\title{
Molecular Chirality and Cloud Activation Potentials of Dimeric a-Pinene Oxidation Products
}

\author{
Aleia Bellcross, Ariana Gray Bé, Franz M. Geiger*, Regan J. Thomson* \\ Department of Chemistry, Northwestern University, Evanston, IL 60208, USA
}

\begin{abstract}
The surface activity of ten atmospherically relevant $\alpha$-pinene-derived dimers having varying terminal functional groups and backbone stereochemistry is reported. We find $\sim 10$ percent differences in surface activity between diastereomers of the same dimer, demonstrating that surface activity depends upon backbone stereochemistry. Octanol-water $\left(K_{O W}\right)$ and octanolammonium sulfate partitioning coefficient $\left(K_{O A S}\right)$ measurements of our standards align well with the surface activity measurements, with the more surface-active dimers exhibiting increased hydrophobicity. Our findings establish a link between molecular chirality and cloud activation potential of secondary organic aerosol particles. Given the diurnal variations in enantiomeric excess of biogenic emissions, possible contributions of such a link to biosphere:atmosphere feedbacks as well as aerosol particle viscosity and phase separation are discussed.
\end{abstract}

*Corresponding authors: f-geiger@northwestern.edu; r-thomson@northwestern.edu 
Introduction. Secondary organic aerosols (SOA) constitute $20-90 \%$ of submicron particulate matter in the atmosphere, where they influence radiative forcing by scattering and absorbing UV radiation, and by activating cloud formation. ${ }^{1,2,3,4}$ Despite this importance, a continued low level of scientific understanding places secondary organic aerosols among the least understood components of the climate system. ${ }^{5,6,7}$ One key unknown concerns the oligomeric species that form from various accretion reactions between atmospheric oxidation products of biogenic volatile organic compounds. ${ }^{8,9,10}$ Such high molecular weight compounds are estimated to contribute up to three quarters of aerosol organic mass. ${ }^{11,12}$ Their long carbon backbones and polar terminal functional groups are reminiscent of commercial surfactants, and like biological lipids they contain stereogenic carbon atoms from their pro-chiral and chiral molecular progenitors, such as isoprene, $\alpha$-pinene, and $\beta$-caryophyllene.

Just like the well-known role of chirality in determining the materials properties of many industrial polymers, ${ }^{13,14}$ backbone stereochemistry could arguably have an important role in determining climate-relevant properties of atmospheric aerosols. ${ }^{15,16}$ Here, we hypothesize that surface activity may differ among stereoisomers, and that certain chiral oligomers may be more surface active than their monomeric precursors, some of which have already been shown to be considerably surface active on their own. ${ }^{17}$ This possibility is especially intriguing given that the enantiomeric ratio of chiral monoterpenes like $\alpha$-pinene (i.e., the ratio of $(-)-\mathbf{1}$ to $(+)-\mathbf{1}$, Figure 1 ) has been shown to be highly variable in the atmosphere and dependent on region, vegetation, temperature, time of day, and plant stress. ${ }^{18,19,20,21,22,23,24}$ Since surface activity is a major determinant of cloud activation through the lowering of the critical supersaturation required for cloud droplet activation, ${ }^{25,26,27,28,29}$ a link between molecular chirality and cloud activation could perhaps be thought of as a contributing factor in biosphere:atmosphere feedbacks like the ones 
elucidated for rainforest aerosols. ${ }^{30}$ Such a link may also help improve atmospheric models, which have been shown to underestimate cloud condensation nuclei production by as much as $30-50 \%$ in some cases if surfactants were excluded..$^{31,32}$

There is little to no difference in gas-phase reactivity towards atmospheric oxidants between enantiomers of chiral biogenic volatile organic compounds, ${ }^{33}$ suggesting that once released into the atmosphere, $(-)$ - and $(+)-\alpha$-pinene react to form oxidation products at the same rate. For $(-)-\alpha$-pinene $[(-)-\mathbf{1}]$, this process (Figure 1A) begins with an initial conversion to carbonyl-containing first-generation oxidation products such as pinonaldehyde (2), pinonic acid (3), hydroxy-pinonaldehyde (4), hydroxy-pinonic acid (5), and pinic acid (6). $(+)$ - $\alpha$-Pinene $[(+)-$ 1], on the other hand, affords the enantiomeric series of products (i.e., ent-2-6). The stereochemistry of the first-generation oxidation products is then retained in the subsequent aerosol particles, as has been shown for both $\alpha$-pinene and isoprene derived SOA. ${ }^{16,34}$ While there has been some speculation as to the possible impacts of oligomer backbone stereochemistry on the physical properties and climate-relevant outcomes of $\mathrm{SOA},{ }^{35,36,37}$ quantitative experimental evidence has yet to be acquired using authentic standards. Furthermore, models often still consider the two separate enantiomers of biogenic volatile organic compounds as one species, disregarding the influence of compound stereochemistry on reactivity. ${ }^{38}$

If one draws the comparison of atmospheric oligomers to industrial polymers - whose physical properties depend on polymer tacticity and where controlling tacticity is therefore of paramount importance ${ }^{13,14}$ — the potential impact of oligomer stereochemistry on climate-relevant properties of atmospheric aerosols becomes apparent. For example, as depicted in Figure 1B, dimerization and oligomerization of monomers derived from a single enantiomeric source (i.e., ()-1 or (+)-1) leads to homochiral secondary organic material (SOM; the specific constituents within 
SOA) as shown for scenarios I and III (denoted as all blue or all red balls). The distribution of stereoisomers becomes more complex when mixtures of enantiomeric monomers are present, as seen in scenario II. Here, initial dimerization may lead to self-condensation (i.e., blue with blue or red with red) or may lead to crossed condensation between the two enantiomeric species to generate diastereomeric dimers of mixed chiral origin (i.e., blue with red). Subsequent accretion reactions may then proceed in either the same or opposite enantiomeric series, ultimately leading to a complex mixture of oligomers of mixed chiral origin. The relative rates of these stereochemical processes are, as far as we know, unknown at this time and no data exists regarding the physical properties of these stereochemically distinct species.

While interest in investigating chirality and oligomeric species within organic aerosols has grown, a lack of authentic standards limits our capabilities to probe oligomer formation, physical properties, and their overall role in atmospheric processes. Thus, our efforts to synthesize such compounds is motivated by the need for these standards within the atmospheric chemistry community. ${ }^{10,39,40} \mathrm{With}$ a focus on $\alpha$-pinene-derived oligomeric species putatively identified in ambient secondary organic aerosol particles, ${ }^{40,41,42,43,44,45,46}$ and as a first step towards investigating complex oligomers, we report herein the synthesis and evaluation of $\alpha$-pinenederived dimers formed by the homocoupling or cross-coupling of stereochemically defined monomers by either an aldol reaction or esterification process (Figure 1C). Subsequent measurements of the interfacial tension depression propensity of our standards, coupled to octanol-water and octanol-ammonium sulfate partitioning coefficient measurements, establish, for the first time, a dependency of cloud activation potential on backbone stereochemistry. 


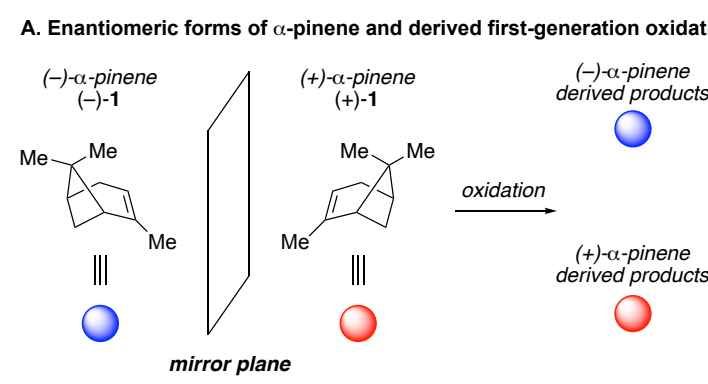

B. Dimerization and oligomerization processes generate complex SOM

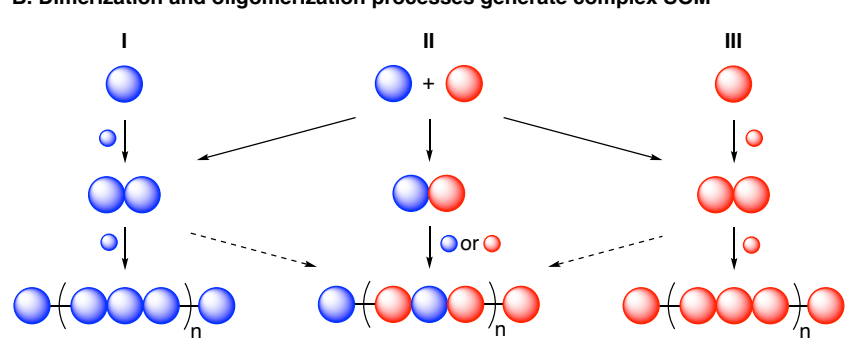

homochiral SOM
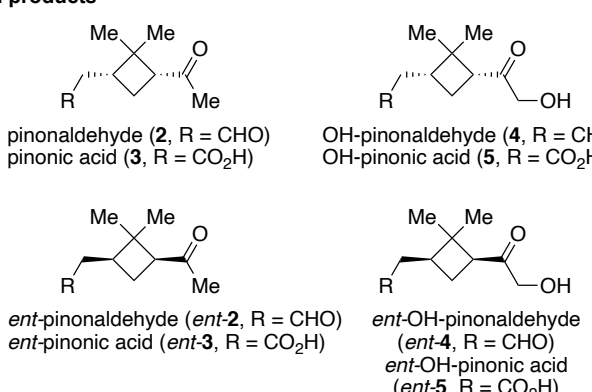

C. Aldol and ester dimers investigated in this study
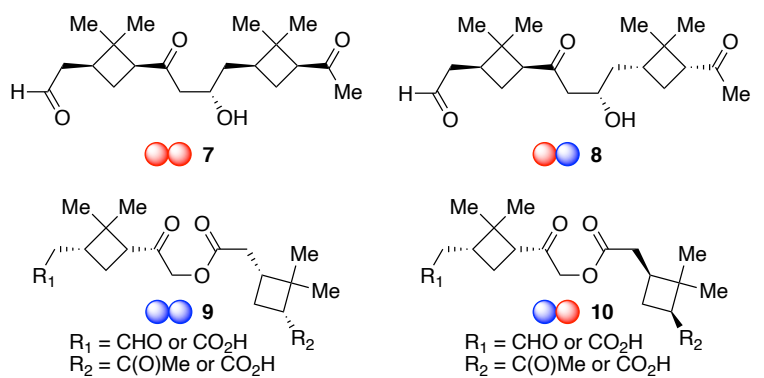

Figure 1. A. $\alpha$-Pinene is a chiral terpene that exists in two enantiomeric forms $[(-)-\mathbf{1}$ and (+)-1)] related through reflection by a mirror plane. Both enantiomers may be present in the atmosphere at varying ratios and undergo oxidation processes initiated by ozone or hydroxyl radicals to yield the corresponding enantiomeric first-generation oxidation products (e.g., 2-6 and ent-2-ent-6). In this Figure, and in subsequent Figures, blue or red balls are used to codify the relationship of compounds relative to the enantiomeric forms of $\alpha$-pinene. B. First-generation oxidation products derived from $\alpha$-pinene react with each other through so-called accretion reactions to form complex dimeric and oligomeric species that constitute significant quantities of material present within secondary atmospheric aerosol particles. For enantiomerically-pure monomers these growth processes will form homochiral products (i.e., scenarios I and II) whose backbone are derived from a single source of chirality (i.e., blue reacts with blue and red reacts with red). In contrast, for racemic or scalemic mixtures of monomers, accretion reactions may take place between molecules derived from the same enantiomeric form of $\alpha$-pinene (i.e., as in scenarios I and III) or between molecules derived from the opposite enantiomers of $\alpha$-pinene (i.e., scenario II where blue reacts with red). For this more complicated sequence of reactions, the corresponding dimers and oligomers formed may possess backbones of mixed chiral origin. C. Specific examples of diastereomeric dimeric species formed by aldol and esterification accretion reactions between monomers derived from either the same (i.e., 7 and $\mathbf{9}$ ) or opposite (i.e., 8 and 10) enantiomeric forms of $\alpha$-pinene. 


\section{Results and Discussion.}

Synthesis of Dimer Standards. Our synthesis of the two dimers formed by an aldol reaction commenced with ozonolysis of $(+)$ - $\alpha$-pinene $[(+)-1]$ under Schreiber's conditions ${ }^{47}$ to deliver dimethylacetal 11, which served as a branch point for stereodivergent access to the diastereomeric aldol adducts 7 and $\mathbf{8}$ (Figure 2A). Initial efforts sought to couple 11 with ent-pinonaldehyde (ent2) via its lithium enolate, but the aldol adduct was produced as a 1:1 mixture of epimeric secondary alcohols that proved difficult to separate. While it is not clear whether the configuration of this hydroxyl group is important, we desired to produce material that was isomerically-pure. To achieve this goal, we utilized Paterson's procedure for stereocontrolled aldol reactions via (-)-Bchlorodiisopinocampheylborane [(-)-DIP-Cl] derived boron enolates. ${ }^{48,} 49$ The dimethylacetal protecting group within the products was cleaved in a subsequent hydrolytic step. Thus, coupling 11 with ent-pinonaldehyde (ent-2) delivered aldol dimer 7 in 56\% yield as an 8:1 ratio of alcohols over two steps (the configuration of the formed hydroxyl stereocenter was defined based on analogy). ${ }^{48,49}$ By simply using pinonaldehyde (2) in the reaction with $\mathbf{1 1}$ we were able to access the diastereomeric aldol dimer $\mathbf{8}$ in a controlled manner. Both compounds were isolated as highly viscous, honey-like oils at room temperature and ambient pressure.

Our stereodivergent synthesis of the ester-linked dimers commenced from (-)-myrtenol (12) as a common starting material. An initial Steglich esterification ${ }^{50}$ of 12 with pinonic acid (3) gave ester 13 in $87 \%$ yield. The methyl ketone within 13 was converted to its enol silane, and the resultant unpurified compound was exposed to ozonolysis conditions to generate a separable mixture of acid-aldehyde 14 and keto-aldehyde 15 in $42 \%$ and $33 \%$ yield, respectively. Hypochlorite-mediated oxidation of each of these compounds converted the aldehyde functional group into the corresponding carboxylic acids, ${ }^{51} 16$ and 17 (from 14 and 15, respectively), in an 
efficient manner. Access to the diastereomeric suite of compounds (i.e., compounds 19-22) was achieved using the same sequence of reactions but employed ent-pinonic acid (ent-3) in the initial Steglich esterification. Compounds 14, 21, and 22 were isolated as white, waxy powders; while the rest of the compounds exist as highly viscous, honey-like oils at room temperature and ambient pressure (see Supporting Information for photos of representative samples).

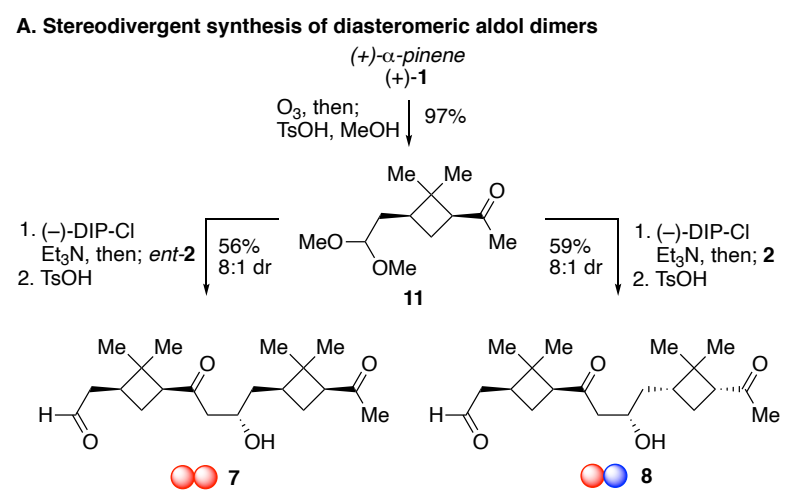

B. Stereodivergent synthesis of diastereomeric ester dimers

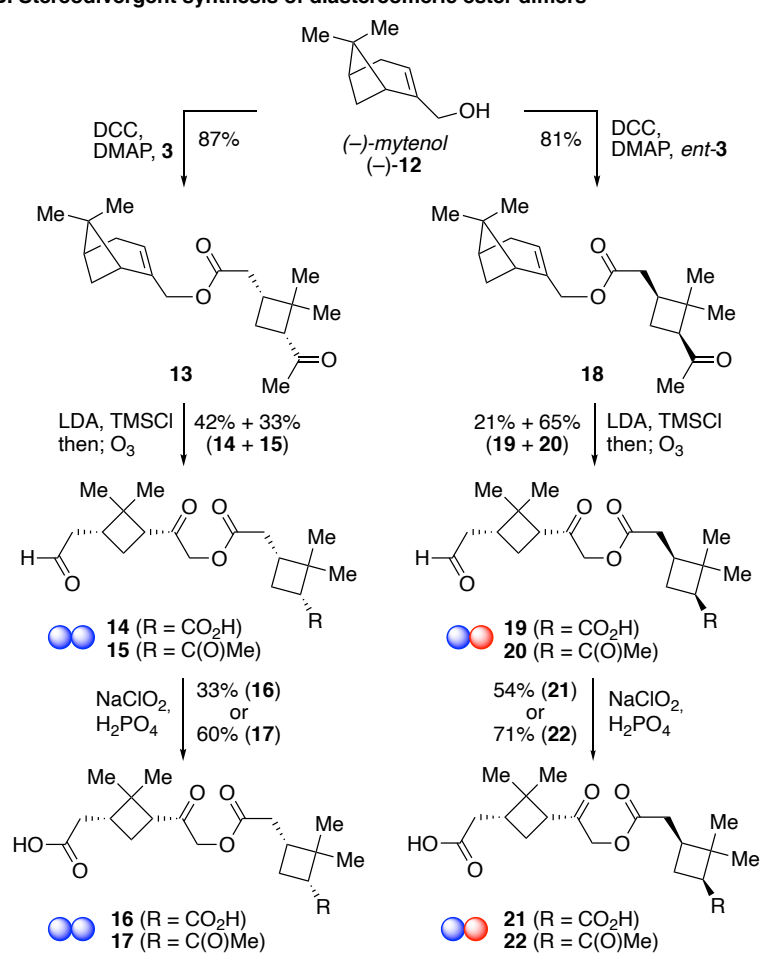

Figure 2. A. Stereodivergent synthesis of the diastereomeric aldol dimers. B. Stereodivergent synthesis of the diastereomeric ester dimers. 
Hydrate Formation of Aldehydes. In previous work, we demonstrated the propensity of terpene oxidation products containing aldehyde groups to exist in equilibrium with their hydrate form when in aqueous environments. ${ }^{17}$ Here, we used ${ }^{1} \mathrm{H}$ NMR spectroscopy to monitor solutions of compounds 7, 14, and 15 suspended in $\mathrm{D}_{2} \mathrm{O}$ with and without $100 \mathrm{mM}$ ammonium sulfate. All three compounds were sparingly soluble, but we did observe hydrate formation at an approximately 1:1.2 ratio of aldehyde to hydrate after 10 minutes for both compounds $\mathbf{1 4}$ and $\mathbf{1 5}$, which was unchanged when measured again after 24 hours. The addition of ammonium sulfate had no effect on the aldehyde:hydrate ratio. Due to low solubility, the signal to noise ratio was too poor for compound 7 to quantify the exchange ratio, but we can safely assume it behaves similarly to the dimers measured here and its monomer precursor pinonaldehyde, measured in our previous study. ${ }^{17}$ Likewise, we assume hydrate formation for the diastereomeric series follows the same trends.

Dynamic Surface Tension Measurements. Dynamic surface tension measurements taken over 10-minute time periods using pendant drop tensiometry were carried out following procedures previously outlined by this group. ${ }^{17,52}$ The dimers were suspended in both deionized water and 1.0 M ammonium sulfate solution, the latter employed to replicate the high concentrations of inorganic species in the atmospheric SOA particle bulk phase. ${ }^{53,54}$ The surface tension of the $1.0 \mathrm{M}$ ammonium sulfate solution-1.0 M being chosen based on our previous estimate of the upper limit of salts in SOA particles ${ }^{17}$-is approximately $75 \mathrm{mN} \mathrm{m}^{-1}$, compared to that of pure water $(72.8 \mathrm{mN}$ $\mathrm{m}^{-1}$ ). As atmospheric aerosols and their proxies are most typically studied with some inorganic content,${ }^{2}$ herein we highlight the data collected in ammonium sulfate solution (1.0 $\mathrm{M}$ ammonium sulfate solution $=\mathrm{pH}$ 5.6); measurements taken in pure water (fresh Millipore water $=\mathrm{pH} 8.8) \mathrm{can}$ be found in the Supporting Information. The concentration of the dimers in the $1.0 \mathrm{M}$ ammonium 
sulfate solution ranged from $0.01 \mathrm{mM}$ to $0.1 \mathrm{mM}$, above which they were found to be insoluble. An activated SOA particle can contain between an estimated 1-500 mM of total organic material, meaning the concentration of one individual organic species is likely to be lower than that range. ${ }^{55}$ The concentration ranges surveyed here were therefore based both on these relevant atmospheric estimations and individual compound solubility.

Across our suite of standards, the data reveals enhanced surface activity of the dimer species when compared to their monomer precursors. ${ }^{17}$ We began our investigations by conducting a comparison between ent-pinonaldehyde (ent-2) and its corresponding aldol dimer 7. At $0.1 \mathrm{mM}$ in $1.0 \mathrm{M}$ ammonium sulfate, the aldol addition dimer 7 exhibited a relative surface tension depression roughly $9 \%$ greater than its monomer precursor pinonaldehyde (ent-2) at the same concentration (Figure 3). Even when measured at $1.0 \mathrm{mM}$, a concentration ten times that of the dimer species, none of the $\alpha$-pinene derived monomer species measured in a previous study showed a greater surface tension depression than the dimers measured here (pinonaldehyde showed only an $8.6 \%$ decrease at $1.0 \mathrm{M}$ in $1.0 \mathrm{M}$ ammonium sulfate). ${ }^{17}$ The propensity of the dimers to populate the droplet surface is in agreement with studies which have observed a "crusting effect," wherein during liquid liquid phase separation (LLPS) oligomers populate the surface of particles and over time form a shell-like structure. ${ }^{56,57}$ The significant difference in surface tension suppression observed between the monomeric aldehyde ent-2 and its dimeric adduct $\mathbf{7}$ also serves to highlight the limitations of correlating $\mathrm{O}: \mathrm{C}$ ratios of compounds with physical properties, a practice that is common in the field of atmospheric science. ${ }^{58,59,60}$ Our comparison here shows clearly that two species with identical O:C ratio can have dramatically different climate-relevant properties. 
As our group has previously illustrated, the presence of ammonium sulfate in conjunction with $\alpha$-pinene oxidation products depresses the surface tension by as much as $4-5 \%$ more than when measured in pure water. ${ }^{17}$ This trend is replicated to an even greater degree here: relative to pure water, the surface tension of a $0.1 \mathrm{mM}$ solution of the aldol addition dimer 7 in $1.0 \mathrm{M}$ ammonium sulfate is depressed by $8 \%$, compared to a $0.1 \%$ decrease at the same concentration in water (see Supporting Information Figure S2J). This phenomenon can be described by the "salting out" effect, wherein the presence of inorganic species in the bulk lowers the solubility of organic species, driving them to the surface of the droplet to form an organic rich crust. ${ }^{53,54,61,62}$

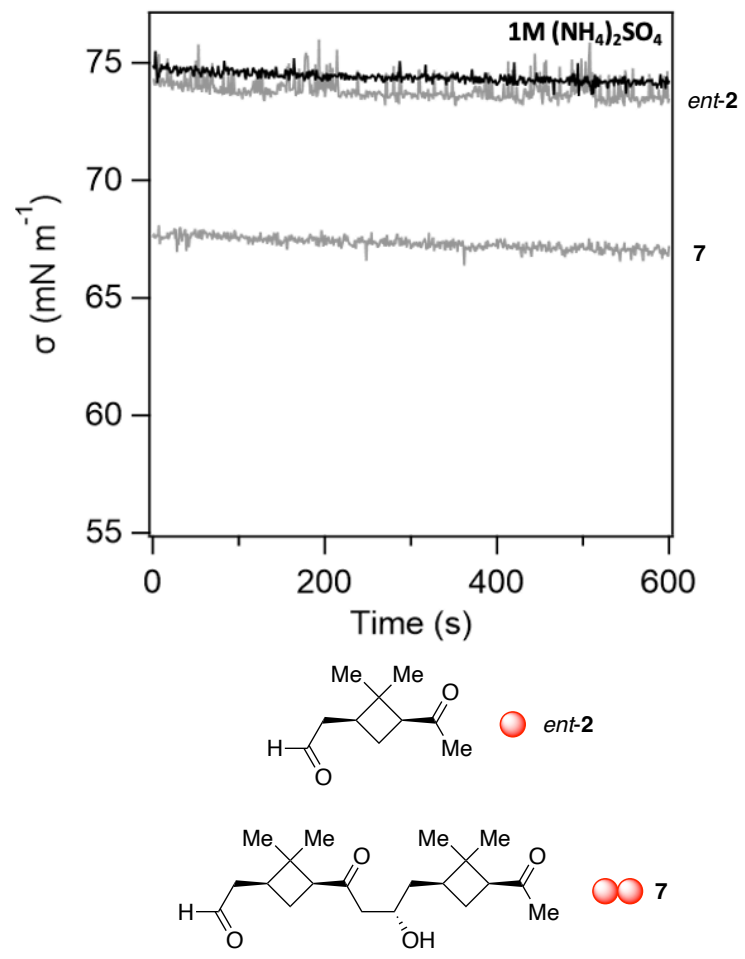

Figure 3. Surface tension $(\sigma)$ over a 10-minute period for ent-pinonaldehyde (ent-2, top grey trace) and its aldol dimer (7, bottom grey trace) at $0.1 \mathrm{mM}$ in $1.0 \mathrm{M}\left(\mathrm{NH}_{4}\right)_{2} \mathrm{SO}_{4}$ solution. The black trace shows the reference surface tension of $1.0 \mathrm{M}\left(\mathrm{NH}_{4}\right)_{2} \mathrm{SO}_{4}$. 
We next turned our attention to investigating the consequences of backbone stereochemistry on surface tension suppression by comparing our suite of dimeric adducts derived from either the same enantiomer of $\alpha$-pinene or from the opposite enantiomeric forms (Figure 4). Figure 4 shows that the relative surface tension depression differences seen across our suite of diastereomeric pairs is quantifiable and, in many cases, the magnitude of the observed difference is significant.
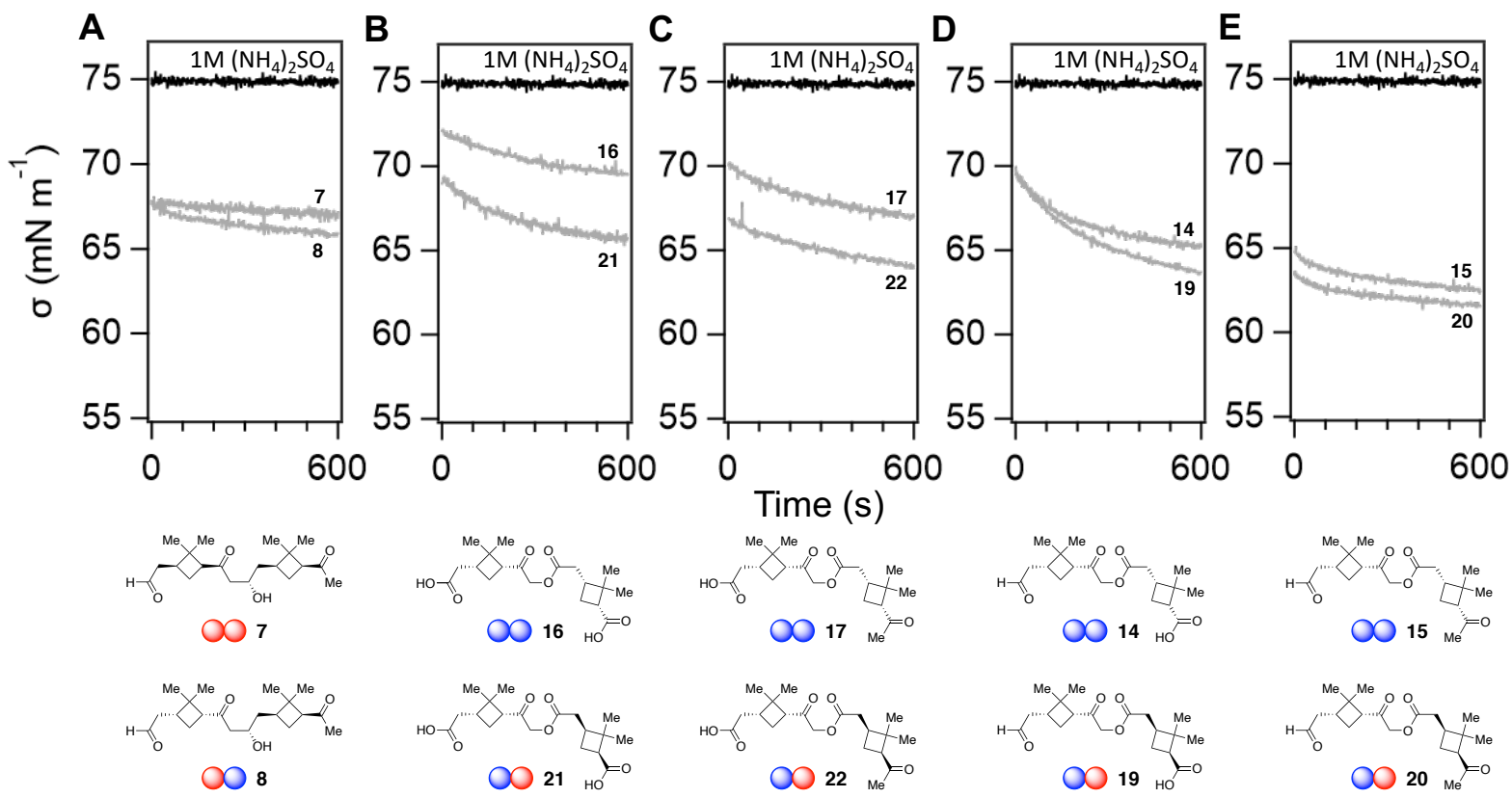

Figure 4. Surface tension $(\sigma)$ over a 10-minute period for each of the compounds shown. A. Aldol addition dimers,

B. Acid-acid ester dimers, C. Acid-ketone ester dimers, D. Aldehyde-acid ester dimers, E. Aldehyde-ketone ester dimers. Each compound was $0.1 \mathrm{mM}$ in a $1 \mathrm{M}\left(\mathrm{NH}_{4}\right)_{2} \mathrm{SO}_{4}$ solution and each trace is an average of 5-7 measurements. The black trace shows the reference surface tension of $1.0 \mathrm{M}\left(\mathrm{NH}_{4}\right)_{2} \mathrm{SO}_{4}$.

In each case, the dimeric adducts derived from opposite enantiomers of $\alpha$-pinene show a greater surface tension depression than their diastereomer counterparts. For all compounds, the difference between diastereomeric pairs exceeds the error in each measurement, which ranged from $0.11-0.45 \mathrm{mN} \mathrm{m}^{-1}$. The two aldol dimers 7 and 8 displayed similar values of $62.57 \mathrm{mN} \mathrm{m}^{-1}$ 
(7) and $61.53 \mathrm{mN} \mathrm{m}^{-1}(\mathbf{8})$ (Figure 4A), while the ester dimers displayed variable degrees of surface tension suppression that appeared to follow a general trend with compound polarity (Figures 4BE). The magnitude of the difference between diastereomers varies between compounds, with the largest relative difference being $6.7 \pm 0.8 \%$ between the acid-acid ester dimer diastereomers (compounds 16 and 21) (Figure 4A), and the smallest being $1.4 \pm 0.3 \%$ between the aldehydeketone ester dimer diastereomers (compounds 15 and 20) (Figure 4E). Repeating the measurements at $0.5 \mathrm{mM}$ in pure water gave the same trend, with some deviations at lower concentrations (see Supporting Information Figure S2).

We attempted to fit the Szyszkowski-Langmuir equation to concentration-dependent surface tension isotherms (see Supporting Information Figure S4) following the procedures outlined in our previous work. ${ }^{17}$ However, for all but one of the compounds the fit was not satisfactory, indicating this idealized model is inadequate to describe the complex systems studied here. We were therefore unable to estimate the surface area per adsorbed molecule or the free energy of adsorption.

Partitioning Coefficients. To gain insight as to the influence of hydrophobicity on the surface activity of the dimers, we determined the partitioning coefficients for our suite of compounds between octanol and pure water $\left(K_{O W}\right)$, and between octanol and 1.0 M ammonium sulfate solution $\left(K_{O A S}\right)$. To determine $K_{O A S}$, each compound was prepared in triplicate at $3 \mathrm{mM}$ in a 1:1 $1.0 \mathrm{M}$ ammonium sulfate:1-octanol solution and sonicated in conical vials for $\sim 24$ hours to allow equilibration. Subsequently, $0.1 \mathrm{~mL}$ aliquots were taken from the 1-octanol phase of each vial and diluted to $0.5 \mathrm{~mL}$ with $\mathrm{HPLC}$ grade $\mathrm{MeOH}$. Samples were then analyzed quantitatively using negative mode ESI-LCMS using an Agilent reverse-phase C18 column to determine the molar 
fraction of substrate present within the octanol phase. Octanaol-ammonium sulfate partitioning coefficients were then calculated according to ${ }^{63}$

$$
\log \left(K_{O A S}\right)=\log \left(\frac{M_{O}}{M_{A S}}\right)
$$

where $M_{O}$ is the concentration of the organic species in the octanol phase and $M_{A S}$ is the concentration of the organic in the ammonium sulfate phase. The corresponding $K_{O W}$ values were determined in an analogous manner, but pure water was used in place of the $1.0 \mathrm{M}$ ammonium sulfate solution. Complete experimental details are outlined in the Supporting Information.

Table 2 gives the results of the partitioning coefficient experiments, where a more positive value for $\log K_{O W}$ or $\log K_{O A S}$ corresponds to a higher concentration of compound in the octanol phase, and therefore an increased hydrophobicity. ${ }^{63}$ The values correspond well with the surface tension measurements, in that the compounds with the more positive values (i.e., compounds 14, 19, 15, and 20) are most surface active. Similar to the surface tension measurements, small differences in the $\log K_{O W}$ or $\log K_{O A S}$ values between diastereomers were also noted. With the exception of the diacid ester dimers (i.e., compounds 16 and 21), the least surface active pair in our suite, the diastereomers of mixed chiral origin derived from both $(+)$ - and $(-)$ - $\alpha$-pinene (red and blue balls), showed slightly more positive $\log K_{O A S}$ and $\log K_{O W}$ values than their counterparts derived from a single enantiomer of $\alpha$-pinene (red or blue balls). The largest difference for both the $\log K_{O A S}(0.5 \pm 0.01)$ and $\log K_{O W}(0.4 \pm 0.01)$ values was seen between the aldehyde acid dimer diastereomers (i.e., compounds 14 and 19). Studies of synthetic polymers have shown that changes in tacticity can alter the hydrophilicity of the polymer, ${ }^{13,14}$ and we assert a similar phenomenon may help to explain the difference in surface activity between the diastereomers studied here. This effect may be of even greater importance when considering higher order oligomers, where increased opportunity for structural variability may lead to larger differences in hydrophobicity. 
These differences in solubility may be of importance when considering the LLPS process in secondary organic aerosol ${ }^{64,65,66}$ as well. Oligomeric species in SOA particles have been cited to be active in the LLPS process-during which lower volatility, hydrophobic organic species separate from the bulk to create an organic shell-like morphology around an aqueous core. ${ }^{56,57,67}$ Future work is needed to examine the effects of backbone stereochemistry on the LLPS of atmospherically-relevant oligomers like those studied here. We do note that on average, the $\log K_{O A S}$ values are slightly more negative than the $\log K_{O W}$ values, an unexpected result based on the observed decreased solubility in ammonium sulfate solution. However, this difference is much smaller than the thermal energy at $300 \mathrm{~K}$, and therefore not an issue of significance.

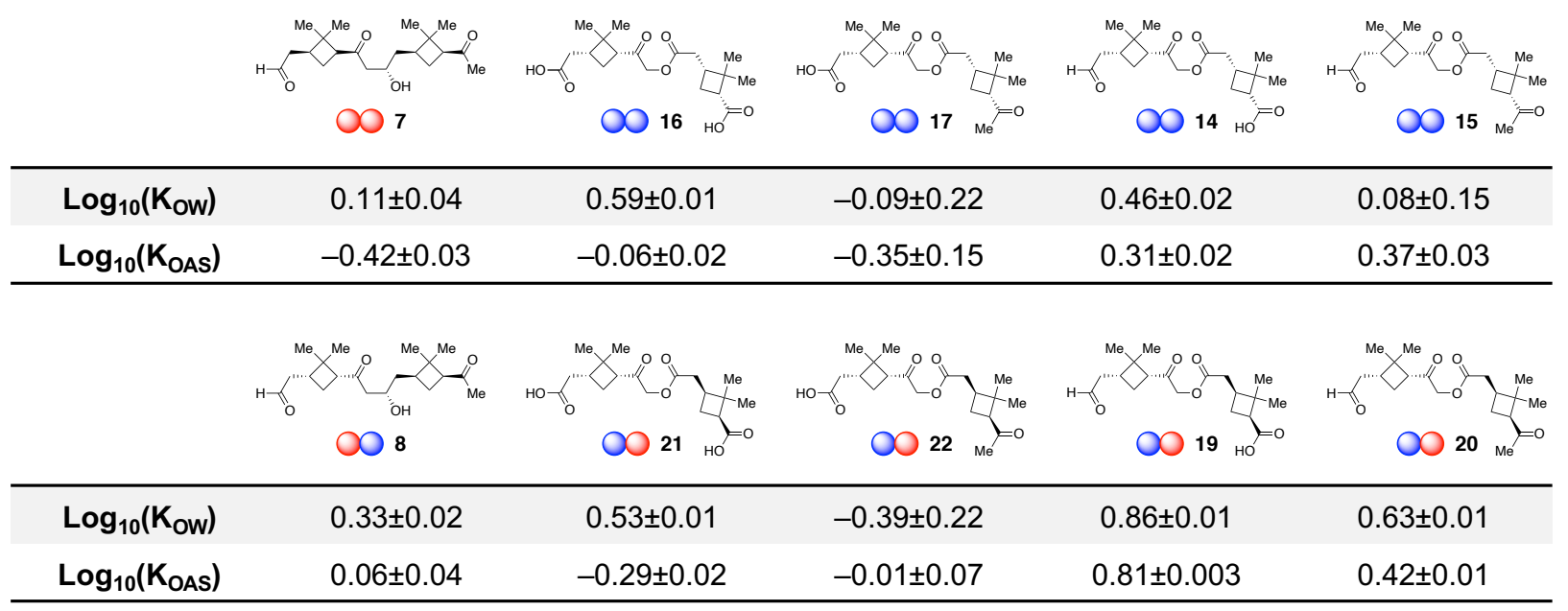

Table 2. Octanol water partitioning coefficients $\left(\log K_{O W}\right)$ and octanol ammonium sulfate partitioning coefficients (log $\left.K_{O A S}\right)$ for each compound determined using negative mode ESI-LCMS. Each value is an average of three measurements.

Implications for Atmospheric Chemistry: Calculation of Cloud Activation Potential. Based on Köhler theory, the cloud condensation nucleation activity of aerosol particles depends on particle size and chemical composition, the latter being the determining factor for smaller particles. ${ }^{68,69,70}$ Surface-active species are of specific importance to cloud activation, given their propensity to depress the surface tension at the moment of particle nucleation. ${ }^{25,29}$ As a result, the 
water vapor supersaturation ratio needed for cloud activation is decreased. Following procedures laid out in our previous work ${ }^{17,52}$ inspired by that of the McNeil group, ${ }^{53,71}$ we calculated the critical supersaturation ratio required for $\mathrm{CCN}$ formation $\left(s_{c}^{*} / s_{c}\right)$ for the dimer standards using the following equation: ${ }^{6}$

$$
\left(s_{c}^{*} / s_{c}\right)=\left(\sigma / \sigma_{\mathrm{w}}\right)^{3 / 2}
$$

Here, $\sigma$ is the surface tension of a given solute in an aqueous solution and $\sigma_{\mathrm{w}}$ is the surface tension of pure water at $20{ }^{\circ} \mathrm{C}\left(72.8 \mathrm{mN} \mathrm{m}^{-1}\right)$. We note that this equation disregards the bulk to surface partitioning of solute particles, which directly influences the Raoult effect and can raise the critical supersaturation ratio, eclipsing any potential lowering due to surface tension depression. ${ }^{68,71}$ However, when the solute composition in the particle bulk is comprised primarily of inorganic species, bulk-to-surface partitioning may be limited and the solute concentration in the bulk remains constant. ${ }^{53}$ Additionally, the formation of an organic crust layer over an inorganic aqueous core via liquid-liquid phase separation, a process attributed to oligomeric compounds like those studied here, ${ }^{56,57,67,72,73}$ may also limit surface-to-bulk partitioning. ${ }^{28,}{ }^{74}$ Based on these considerations, we make the assumption in this idealized study that the effects on the critical supersaturation ratio are primarily due to surface tension depression.

Table 1 shows the calculated critical supersaturation ratios for each of the dimer standards. For each of the compounds, the surface tension value $(\sigma)$ was taken as the average of the last 20 seconds of the 10-minute period (an average of 3-5 measurements). The most surface-active of the dimer species, the aldehyde-ketone ester dimer 20, boasts a $s_{c}^{*} / s_{c}$ value of $0.779 \pm 0.002$ (a 22 percent decrease relative to aqueous ammonium sulfate). These $s_{c}^{*} / s_{c}$ values are comparable to the $0.71 \pm 0.001$ ( 29 percent decrease) for $\beta$-caryophyllene aldehyde, the most surface active of the $\beta$-caryophyllene oxidation products previously measured by this group. ${ }^{17}$ In comparing 
diastereomers, the largest difference in critical supersaturation ratios is $9.43 \pm 0.005$ percent between the pair of diastereomeric ester dimers $\mathbf{1 6}$ and 21, each of which possesses two carboxylic acid groups. We note that in atmospheric SOA particles these compounds exist in complex mixtures with other dimers, higher-order oligomers, and VOCs, and not in pure one-component systems. Yet, the clear differences in $\mathrm{CCN}$ activation potential between pure solutions of diastereomers highlights the importance of studying the effect of backbone stereochemistry on the physical properties of atmospheric compounds.

\begin{tabular}{|c|c|c|c|c|c|}
\hline Conc. (mM) & 007 & $0016 \mathrm{Hо}$ & OO 17 me $^{=}=0$ & OO 14 но & OO $15 \mathrm{me}^{=}$ \\
\hline 0 & $1.044 \pm 0.004$ & $1.028 \pm 0.003$ & $1.044 \pm 0.004$ & $1.038 \pm 0.004$ & $1.028 \pm 0.005$ \\
\hline 0.01 & $1.004 \pm 0.003$ & $1.009 \pm 0.003$ & $1.031 \pm 0.005$ & $0.989 \pm 0.006$ & $0.987 \pm 0.004$ \\
\hline 0.1 & $0.883 \pm 0.003$ & $0.933 \pm 0.002$ & $0.884 \pm 0.004$ & $0.849 \pm 0.002$ & $0.795 \pm 0.002$ \\
\hline Conc. (mM) & 008 & OO 21 но $=$ & OO22 ме ме $=0$ & O 19 но & О 20 ма \\
\hline 0 & $1.036 \pm 0.005$ & $1.041 \pm 0.004$ & $1.045 \pm 0.007$ & $1.040 \pm 0.007$ & $0.992 \pm 0.004$ \\
\hline 0.01 & $1.003 \pm 0.004$ & $1.037 \pm 0.004$ & $0.999 \pm 0.004$ & $1.030 \pm 0.004$ & $0.955 \pm 0.004$ \\
\hline 0.1 & $0.851 \pm 0.002$ & $0.845 \pm 0.003$ & $0.825 \pm 0.002$ & $0.817 \pm 0.002$ & $0.779 \pm 0.002$ \\
\hline
\end{tabular}

Table 1. Supersaturation ratios $\left(s_{c}^{*} / s_{c}\right)$ for the series of $\alpha$-pinene-derived dimers. The top row shows compounds derived from the same enantiomers of $\alpha$-pinene, while the bottom row shows compounds derived from opposite $\alpha$ pinene enantiomers. All compounds were measured at $0-0.1 \mathrm{mM}$ in a $1.0 \mathrm{M}$ solution of $\left(\mathrm{NH}_{4}\right)_{2} \mathrm{SO}_{4}$.

Conclusions. The results of our work point to the necessity of considering the stereochemistry of biogenically emitted VOCs and their subsequent oxidation products when determining the physical properties of SOAs and their role(s) in the climate system. The propensity of surfactant-like species to depress the surface tension of an aqueous interface can be described by two factors: the hydrophobicity of the compound and its influence on the interfacial hydrogen bonding network. 
Our surface tension measurements indicate that the surface activity of the $\alpha$-pinene-derived dimers somewhat depends on the backbone stereochemistry of the compounds. Octanol-ammonium sulfate and octanol-water partitioning coefficient measurements show small differences between diastereomers, with the more surface-active dimers derived from a condensation of both (+)- and (-)-1 exhibiting greater hydrophobicity than those derived from a single enantiomer of $\alpha$-pinene (i.e., (+)-1 or (-)-1). These small differences would suggest that solubility plays some role in the increased surface activity of the mixed chirality dimers, however the differences are not so large as to suggest that solubility is solely responsible. Due to changes in the $3 \mathrm{D}$ shape of the dimeric diastereomers, it is not unreasonable to imagine that their orientation at the interface is also different, thus influencing the degree to which they disrupt the hydrogen bonding network. ${ }^{75}$ Future work is needed to establish the absolute orientation of the dimers at the particle interface in order to further explain the observed differences in surface depression propensity. Such molecular studies require chemical bond selectivity, along with structural sensitivity and surface selectivity. As oligomers and their monomeric precursors often share the same or similar O:C ratio, it would be challenging to speciate them using this parameter that is otherwise widely used to describe the overall polarity and properties of organic aerosol particles. ${ }^{58,59,60}$

Our findings indicate that particle surface properties resulting from the presence of $\alpha$ pinene derived dimer species depend in part on the backbone stereochemistry of the oligomeric compounds. Based on our results, climate models may be underestimating cloud activation in scenarios where both enantiomers of a monomeric precursor are present, such as $(+)-$ and $(-)-\alpha-$ pinene, allowing for the formation of various dimers in different quantities that exhibit different surface activities. One can also consider higher-order oligomers, where the potential for increased variability between monomer stereochemistry and a greater dependence on atmospheric 
enantiomeric excess may have a more significant impact on SOA properties than is currently understood. The possibility that changes in enantiomeric excess triggered by plant stress or other exogenous influences could enhance or diminish cloud activation over a forest region may also be considered. Our future synthetic efforts will seek to address this topic by targeting higher order oligomers of differing backbone stereochemistry. In addition, determining the formation rates of specific oligomers in SOA with stereochemical specificity will be essential to better quantify the relationship between atmospheric enantiomeric excess and cloud activation. Given the ample data on how chirality can be used to control properties of polymeric materials and the critical importance of enantiopurity in drug action, particle measurements of viscosity and LLPS should also be performed to determine how they are influenced by molecular chirality. Moreover, surfacespecific measurements are needed to determine how stereochemistry influences interfacial configuration and orientation of these molecules. ${ }^{76}$ Access to the standards highlighted in this work will help to enable such endeavors.

\section{Acknowledgements.}

A.B. and A.G.B. gratefully acknowledge NSF Graduate Research Fellowships. This work was supported by the National Science Foundation (NSF) under Grant No. CHE-1607640 and CHE2003359. This work made use of the IMSERC at Northwestern University, which has received support from the Soft and Hybrid Nanotechnology Experimental (SHyNE) Resource (NSF ECCS1542205), the State of Illinois, and the International Institute for Nanotechnology (IIN). 


\section{Author Contributions.}

FMG and RJT conceived the project, designed the experiments, analyzed data, and wrote the manuscript. $\mathrm{AB}$ and $\mathrm{AGB}$ designed and executed the experiments, analyzed data, and wrote the manuscript.

\section{References.}

1. Kanakidou M., Seinfeld J. H., Pandis S. N., Barnes I., Dentener F. J., Facchini M. C., et al. Organic aerosol and global climate modelling: A review. Atmos. Chem. Phys. 5, 1053-1123 (2005).

2. Hallquist M., Wenger J. C., Baltensperger U., Rudich Y., Simpson D., Claeys M., et al. The formation, properties and impact of secondary organic aerosol: Current and emerging issues. Atmos. Chem. Phys. 9, 5155-5236 (2009).

3. Seinfeld J. H. \& Pandis S. N. Atmospheric chemistry and physics: From air pollution to climate change. John Wiley \& Sons, 2012.

4. Finlayson-Pitts B. J. P. J., J. N. Chemistry of the upper and lower atmosphere. Academic Press: New York, 2000.

5. Donner L. J. \& Large W. G. Climate modeling. Annual Review of Environment and Resources 33, 1-17 (2008). 
6. Cappa C. D., Jathar S. H., Kleeman M. J., Docherty K. S., Jimenez J. L., Seinfeld J. H., et al. Simulating secondary organic aerosol in a regional air quality model using the statistical oxidation model - part 2: Assessing the influence of vapor wall losses. Atmos. Chem. Phys. 16, 3041-3059 (2016).

7. IPCC. Climate change 2013: The physical science basis. Contribution of working group i to the fifth assessment report of the intergovernmental panel on climate change. Cambridge, United Kingdom and New York, NY, USA; 2013.

8. Kalberer M., Paulsen D., Sax M., Steinbacher M., Dommen J., Prevot A. S. H., et al. Identification of polymers as major components of atmospheric organic aerosols. Science 303, 1659-1662 (2004).

9. Kristensen K., Watne Å. K., Hammes J., Lutz A., Petäjä T., Hallquist M., et al. Highmolecular weight dimer esters are major products in aerosols from $\alpha$-pinene ozonolysis and the boreal forest. Environ. Sci. Technol. Lett. 3, 280-285 (2016).

10. Glasius M. \& Goldstein A. H. Recent discoveries and future challenges in atmospheric organic chemistry. Environ. Sci. Technol. 50, 2754-2764 (2016).

11. Couvidat F., Vivanco M. G. \& Bessagnet B. Simulating secondary organic aerosol from anthropogenic and biogenic precursors: Comparison to outdoor chamber experiments, 
effect of oligomerization on SOA formation and reactive uptake of aldehydes. Atmos. Chem. Phys. 18, 15743-15766 (2018).

12. Ehn M., Thornton J. A., Kleist E., Sipilä M., Junninen H., Pullinen I., et al. A large source of low-volatility secondary organic aerosol. Nature 506, 476 (2014).

13. Katsumoto Y., Kubosaki N. \& Miyata T. Molecular approach to understand the tacticity effects on the hydrophilicity of poly(n-isopropylacrylamide): Solubility of dimer model compounds in water. J. Phys. Chem. B 114, 13312-13318 (2010).

14. Nishi K., Hiroi T., Hashimoto K., Fujii K., Han Y.-S., Kim T.-H., et al. Sans and dls study of tacticity effects on hydrophobicity and phase separation of poly(n-isopropylacrylamide). Macromolecules 46, 6225-6232 (2013).

15. Martinez I. S., Peterson M. D., Ebben C. J., Hayes P. L., Artaxo P., Martin S. T., et al. On molecular chirality within naturally occurring secondary organic aerosol particles from the central Amazon basin. Phys. Chem. Chem. Phys. 13, 12114-12122 (2011).

16. Cash J. M., Heal M. R., Langford B. \& Drewer J. A review of stereochemical implications in the generation of secondary organic aerosol from isoprene oxidation. Environ. Sci.: Process. Impacts 18, 1369-1380 (2016). 
17. Gray Be A., Upshur M. A., Liu P., Martin S. T., Geiger F. M. \& Thomson R. J. Cloud activation potentials for atmospheric $\alpha$-pinene and $\beta$-caryophyllene ozonolysis products. ACS Cent. Sci. 3, 715-725 (2017).

18. Tarvainen V., Hakola H., Hellén H., Bäck J., Hari P. \& Kulmala M. Temperature and light dependence of the VOC emissions of Scots pine. Atmos. Chem. Phys. 5, 989 (2005).

19. Williams J., Yassaa N., Bartenbach S. \& Lelieveld J. Mirror image hydrocarbons from tropical and boreal forests. Atmos. Chem. Phys. 7, 973 (2007).

20. Williams J., Crowley J., Fischer H., Harder H., Martinez M., Petäjä T., et al. The summertime boreal forest field measurement intensive (HUMPPA-COPEC-2010): An overview of meteorological and chemical influences. Atmos. Chem. Phys. 11, 10599 (2011).

21. Ebben C. J., Shrestha M., Martinez I. S., Corrigan A. L., Frossard A. A., Song W. W., et al. Organic constituents on the surfaces of aerosol particles from southern Finland, Amazonia, and California studied by vibrational sum frequency generation. J. Phys. Chem. A 116, 8271-8290 (2012).

22. Song W., Williams J., Yassaa N., Martinez M., Carnero J. A. A., Hidalgo P. J., et al. Winter and summer characterization of biogenic enantiomeric monoterpenes and anthropogenic 
BTEX compounds at a Mediterranean stone pine forest site. J. Atmos. Chem. 68, 233-250 (2011).

23. Noureddine Y., Song W., Lelieveld J., Vanhatalo A., Bäck J. \& Williams J. Diel cycles of isoprenoids in the emissions of norway spruce, four Scots pine chemotypes, and in boreal forest ambient air during HUMPPA-COPEC-2010. Atmos. Chem. Phys. Discuss. 12, 10425-10460 (2012).

24. Stephanou E. G. A forest air of chirality. Nature 446, 991-991 (2007).

25. Sareen N., Schwier A. N., Lathem T. L., Nenes A. \& McNeill F. Surfactants from the gas phase may promote cloud droplet formation. Proc. Natl. Acad. Sci. U. S. A. 110, 27232728 (2013).

26. Nozière B., Baduel C. \& Jaffrezo J.-L. The dynamic surface tension of atmospheric aerosol surfactants reveals new aspects of cloud activation. Nat. Commun. 5, 3335 (2014).

27. Petters S. S. \& Petters M. D. Surfactant effect on cloud condensation nuclei for twocomponent internally mixed aerosols. J. Geophys. Res.: Atmos. 121, 1878-1895 (2016).

28. Ruehl C. R., Davies J. F. \& Wilson K. R. An interfacial mechanism for cloud droplet formation on organic aerosols. Science (Washington, DC, U. S.) 351, 1447-1450 (2016). 
29. Cruz C. N. \& Pandis S. N. The effect of organic coatings on the cloud condensation nuclei activation of inorganic atmospheric aerosol. J. Geophys. Res.: Atmos. 103, 13111-13123 (1998).

30. Poeschl U., Martin S. T., Sinha B., Chen Q., Gunthe S. S., Huffman J. A., et al. Rainforest aerosols as biogenic nuclei of clouds and precipitation in the Amazon. Science 329, 1513$1516(2010)$.

31. Good N., Topping D. O., Allan J. D., Flynn M., Fuentes E., Irwin M., et al. Consistency between parameterisations of aerosol hygroscopicity and $\mathrm{CCN}$ activity during the rhamble discovery cruise. Atmos. Chem. Phys. 10, 3189-3203 (2010).

32. Irwin M., Good N., Crosier J., Choularton T. W. \& McFiggans G. Reconciliation of measurements of hygroscopic growth and critical supersaturation of aerosol particles in central germany. Atmos. Chem. Phys. 10, 11737-11752 (2010).

33. Nunes F. M. N., Veloso M. C. C., de P. Pereira P. A. \& de Andrade J. B. Gas-phase ozonolysis of the monoterpenoids (s)-(+)-carvone, (r)-(-)-carvone, (-)-carveol, geraniol and citral. Atmos. Environ. 39, 7715-7730 (2005).

34. Ebben C. J., Zorn S. R., Lee S.-B., Artaxo P., Martin S. T. \& Geiger F. M. Stereochemical transfer to atmospheric aerosol particles accompanying the oxidation of biogenic volatile organic compounds. Geophys. Res. Lett. 38, L16807 (2011). 
35. Stokes G. Y., Chen E. H., Buchbinder A. M., Paxton W. F., Keeley A. \& Geiger F. M. Atmospheric heterogeneous stereochemistry. J. Am. Chem. Soc. 131, 13733-13737 (2009).

36. Mikhailov E., Vlasenko S., Martin S., Koop T. \& Pöschl U. Amorphous and crystalline aerosol particles interacting with water vapor: Conceptual framework and experimental evidence for restructuring, phase transitions and kinetic limitations. Atmos. Chem. Phys. 9, (2009).

37. Freney E. J., Adachi K. \& Buseck P. R. Internally mixed atmospheric aerosol particles: Hygroscopic growth and light scattering. J. Geophys. Res.: Atmos. 115, (2010).

38. Guenther A., Hewitt C. N., Erickson D., Fall R., Geron C., Graedel T., et al. A global model of natural volatile organic compound emissions. J. Geophys. Res.: Atmos. 100, 8873-8892 (1995).

39. Liu P., Song M., Zhao T., Gunthe S. S., Ham S., He Y., et al. Resolving the mechanisms of hygroscopic growth and cloud condensation nuclei activity for organic particulate matter. Nat. Commun. 9, 4076 (2018).

40. Witkowski B.\& Gierczak T. Early stage composition of SOA produced by $\alpha$-pinene/ozone reaction: $\alpha$-acyloxyhydroperoxy aldehydes and acidic dimers. Atmos. Environ. 95, 59-70 (2014). 
41. Liggio J. \& Li S.-M. Reactive uptake of pinonaldehyde on acidic aerosols. J. Geophys. Res.: Atmos. 111, D24303 (2006).

42. Zhao R., Aljawhary D., Lee A. K. Y. \& Abbatt J. P. D. Rapid aqueous-phase photooxidation of dimers in the $\alpha$-pinene secondary organic aerosol. Environ. Sci.Technol. Lett. 4, 205-210 (2017).

43. Zhang X., McVay R. C., Huang D. D., Dalleska N. F., Aumont B., Flagan R. C., et al. Formation and evolution of molecular products in $\alpha$-pinene secondary organic aerosol. Proc. Natl. Acad. Sci. 112, 14168-14173 (2015).

44. Müller L., Reinnig M. C., Warnke J. \& Hoffmann T. Unambiguous identification of esters as oligomers in secondary organic aerosol formed from cyclohexene and cyclohexene/ $\alpha$ pinene ozonolysis. Atmos. Chem. Phys. 8, 1423-1433 (2008).

45. Yasmeen F., Vermeylen R., Maurin N., Perraudin E., Doussin J.-F. \& Claeys M. Characterisation of tracers for aging of $\alpha$-pinene secondary organic aerosol using liquid chromatography/negative ion electrospray ionisation mass spectrometry. Environ. Chem. 9, 236-246 (2012).

46. Tolocka M. P., Jang M., Ginter J. M., Cox F. J., Kamens R. M. \& Johnston M. V. Formation of oligomers in secondary organic aerosol. Environ. Sci. Technol. 38, 1428-1434 (2004). 
47. Schreiber S. L., Claus R. E. \& Reagan J. Ozonolytic cleavage of cycloalkenes to terminally differentiated products. Tetrahedron Lett. 23, 3867-3870 (1982).

48. Paterson I. \& Goodman J. M. Aldol reactions of methylketones using chiral boron reagents: A reversal in aldehyde enantioface selectivity. Tetrahedron Lett. 30, 997-1000 (1989).

49. Paterson I., Goodman J. M., Anne Lister M., Schumann R. C., McClure C. K. \& Norcross R. D. Enantio- and diastereoselective aldol reactions of achiral ethyl and methyl ketones with aldehydes: The use of enol diisopinocampheylborinates. Tetrahedron 46, 4663-4684 (1990).

50. Neises B. \& Steglich W. Simple method for the esterification of carboxylic acids. Angew. Chem. Int. Ed. 17, 522-524 (1978).

51. Kraus G. A. \& Roth B. Synthetic studies toward verrucarol. 2. Synthesis of the AB ring system. J. Org. Chem. 45, 4825-4830 (1980).

52. Upshur M. A., Strick B. F., McNeill V. F., Thomson R. J. \& Geiger F. M. Climate-relevant physical properties of molecular constituents for isoprene-derived secondary organic aerosol material. Atmos. Chem. Phys. 14, 10731-10740, 10710 pp. (2014). 
53. Sareen N., Schwier A. N., Shapiro E. L., Mitroo D. \& McNeill V. F. Secondary organic material formed by methylglyoxal in aqueous aerosol mimics. Atmos. Chem. Phys.10,9971016 (2010).

54. Li Z., Williams A. L. \& Rood M. J. Influence of soluble surfactant properties on the activation of aerosol particles containing inorganic solute. J. Atmos. Sci. 55, 1859 (1998).

55. Gerard V., Noziere B., Baduel C., Fine L., Frossard A. A. \& Cohen R. C. Anionic, cationic, and nonionic surfactants in atmospheric aerosols from the Baltic coast at Asko, Sweden: Implications for cloud droplet activation. Environ. Sci. Technol. 50, 2974-2982 (2016).

56. Vaden T. D., Imre D., Beranek J., Shrivastava M. \& Zelenyuk A. Evaporation kinetics and phase of laboratory and ambient secondary organic aerosol. Proc. Natl. Acad.Sci. U. S. A. 108, 2190-2195, S2190/2191-S2190/2195 (2011).

57. Boyd C. M., Nah T., Xu L., Berkemeier T. \& Ng N. L. Secondary organic aerosol (SOA) from nitrate radical oxidation of monoterpenes: Effects of temperature, dilution, and humidity on aerosol formation, mixing, and evaporation. Environ. Sci. Technol. 51, 78317841 (2017).

58. Song M., Ham S., Andrews R. J., You Y. \& Bertram A. K. Liquid-liquid phase separation in organic particles containing one and two organic species: Importance of the average O:C. Atmos. Chem. Phys. 18, 12075-12084 (2018). 
59. Song M., Marcolli C., Krieger U. K., Zuend A. \& Peter T. Liquid-liquid phase separation in aerosol particles: Dependence on $\mathrm{O}: \mathrm{C}$, organic functionalities, and compositional complexity. Geophys. Res. Lett.39, (2012).

60. Aiken A. C., DeCarlo P. F., Kroll J. H., Worsnop D. R., Huffman J. A., Docherty K. S., et al. $\mathrm{O} / \mathrm{C}$ and $\mathrm{OM} / \mathrm{OC}$ ratios of primary, secondary, and ambient organic aerosols with highresolution time-of-flight aerosol mass spectrometry. Environ. Sci. Technol. 42, 4478-4485 (2008).

61. Matijević E. \& Pethica B. A. The properties of ionized monolayers. Part 1.-sodium dodecyl sulphate at the air/water interface. Trans. Faraday Soc. 54, 1382-1389 (1958).

62. Schwier A., Mitroo D. \& McNeill V. F. Surface tension depression by low-solubility organic material in aqueous aerosol mimics. Atmos. Environ. 54, 490-495 (2012).

63. Leo A., Hansch C. \& Elkins D. Partition coefficients and their uses. Chem. Rev. 71, 525$616(1971)$.

64. Ianiro A., Wu H., van Rijt M. M. J., Vena M. P., Keizer A. D. A., Esteves A. C. C., et al. Liquid-liquid phase separation during amphiphilic self-assembly. Nat Chem 11, 320-328 (2019). 
65. Renbaum-Wolff L., Song M., Marcolli C., Zhang Y., Liu P. F., Grayson J. W., et al. Observations and implications of liquid-liquid phase separation at high relative humidities in secondary organic material produced by $\alpha$-pinene ozonolysis without inorganic salts. Atmos. Chem. Phys. 16, 7969-7979 (2016).

66. Song Y.-C., Bé A. G., Martin S. T., Geiger F. M., Bertram A. K., Thomson R. J., et al. Liquid-liquid phase separation and morphologies in organic particles consisting of $\alpha$ pinene and $\beta$-caryophyllene ozonolysis products and mixtures with commercially available organic compounds. Atmos. Chem. Phys. 20, 11263-11273 (2020).

67. Song Y. C., Bé A. G., Martin S. T., Geiger F. M., Bertram A. K., Thomson R. J., et al. Liquid-liquid phase separation and morphologies in organic particles consisting of $\alpha$ pinene and $\beta$-caryophyllene ozonolysis products and mixtures with commercially available organic compounds. Atmos. Chem. Phys. 20, 11263-11273 (2020).

68. Köhler H. The nucleus in and the growth of hygroscopic droplets. Trans. Faraday Soc. 32, 1152-1161 (1936).

69. Sorjamaa R., Svenningsson B., Raatikainen T., Henning S., Bilde M. \& Laaksonen A. The role of surfactants in Köhler theory reconsidered. Atmos. Chem. Phys. 4, 2107 (2004). 
70. Zhao D. F., Buchholz A., Kortner B., Schlag P., Rubach F., Kiendler-Scharr A., et al. Sizedependent hygroscopicity parameter $(x)$ and chemical composition of secondary organic cloud condensation nuclei. Geophys. Res. Lett. 42, 10920-10928 (2015).

71. McNeill V.F., Sareen N. \& Schwier A. N. Surface-active organics in atmospheric aerosols. In: McNeill VF, Ariya PA (eds). Atmospheric and aerosol chemistry. Springer Berlin Heidelberg: Berlin, Heidelberg, 2014, pp 201-259.

72. Roldin P., Liao L., Mogensen D., Dal Maso M., Rusanen A., Kerminen V. M., et al. Modelling the contribution of biogenic volatile organic compounds to new particle formation in the jülich plant atmosphere chamber. Atmos. Chem. Phys. 15, 10777-10798 (2015).

73. Vander Wall A. C., Lakey P. S. J., Rossich Molina E., Perraud V., Wingen L. M., Xu J., et al. Understanding interactions of organic nitrates with the surface and bulk of organic films: Implications for particle growth in the atmosphere. Environ. Sci.: Process. Impacts 20, 1593-1610 (2018).

74. Ovadnevaite J., Zuend A., Laaksonen A., Sanchez K. J., Roberts G., Ceburnis D., et al. Surface tension prevails over solute effect in organic-influenced cloud droplet activation. Nature 546, 637-641 (2017). 
75. Gil P. S. \& Lacks D. J. Effect of surfactant shape on solvophobicity and surface activity in alcohol-water systems. J. Chem. Phys. 145, 204705 (2016).

76. Be A. G., Liu Y., Tuladhar A., Bellcross A. D., Wang Z., Thomson R. J., et al. Surfaceactive $\beta$-caryophyllene oxidation products at the air/aqueous interface. ACS Earth Space Chem. 3, 1740-1748 (2019). 